\title{
Otros sujetos de derecho o personas (?)
}

\author{
Other Subjects of Law or People (?) \\ Outros sujeitos de direito ou pessoas (?)
}

\author{
Franco Ceballos Rosero*
}

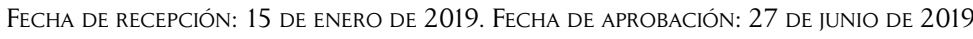

Doi: http://dx.doi.org/10.12804/revistas.urosario.edu.co/sociojuridicos/a.7576

Para citar: Ceballos Rosero, F. (2019). Otros sujetos de derecho o personas (?). Estudios Socio-Jurídicos, 22(1), 321-351.

Doi: http://dx.doi.org/10.12804/revistas.urosario.edu.co/sociojuridicos/a.7576

\section{RESUMEN}

La existencia de nuevos sujetos de derecho o personas es evidente en múltiples ordenamientos jurídicos, ya que, además de las personas naturales y jurídicas, se han abierto camino como sujetos de derecho o personas comunidades étnicas, generaciones futuras, los seres sintientes y algunos ecosistemas con los que la humanidad comparte vida, hábitats y dependencia. Los derechos étnicos, ambientales, de la naturaleza y de protección animal han abierto la posibilidad teórica para desantropologizar el derecho, posibilitando, inclusive, perspectivas teóricas mucho más ambiciosas relacionadas con las inteligencias artificiales, androides/robots o los seres espirituales. El presente documento es una aproximación teórica para una teoría heterogénea del concepto de persona que desborde sus límites antropocéntricos.

Palabras clave: sujetos de derechos (personas), derechos de la naturaleza, seres sintientes, inteligencias artificiales, derechos étnico-territoriales.

* Artículo de reflexión e insumo en la construcción de un anteproyecto de tesis doctoral para una teoría heterogénea del concepto de persona. Texto derivado de los proyectos 1) Reconceptualización del concepto de persona y persona natural desde la perspectiva político-jurídica de los derechos de la naturaleza para la interpretación, enseñanza y uso alternativo del derecho y 2) Nuevos Sujetos de Derecho, una lectura jurídica desde la ciencia ficción (en construcción). Financiados por la Universidad Cooperativa de Colombia.

** Abogado y Magíster en Etnoliteratura de la Universidad de Nariño. Docente Investigador de la Universidad Cooperativa de Colombia, sede Pasto, en temas sociojurídicos relacionados con derechos de la naturaleza, pueblos indígenas y manejo comunitario del agua. Correo electrónico: franco.ceballosr@campusucc.edu.co. ORCID: https://orcid.org/0000-0002-2706-224X 


\section{ABSTRACT}

The existence of new subjects of law or people is evident in multiple legal systems, since in addition to natural and legal persons, ethnic communities, future generations, sentient beings and some ecosystems with which the humanity shares life, habitats and dependency, have opened a place in the legal reflection as if they were persons. The ethnic, environmental, nature and animal protection rights have opened the theoretical possibility to remove anthropological conception from the law, allowing much more ambitious theoretical perspectives related to artificial intelligences, androids/robots or spiritual beings. This document is a theoretical approach for a heterogeneous theory of the concept of person that overflows its anthropocentric limits.

Keywords: Subjects of law (persons), rights of nature, sentient beings, artificial intelligence, ethnic-territorial rights.

\section{RESUMO}

A existência de novos sujeitos de direito ou pessoas é evidente em múltiplos ordenamentos jurídicos, pois para além das pessoas naturais e jurídicas, se têm aberto caminho como sujeitos de direito ou pessoas comunidades étnicas, gerações futuras, os seres sencientes e alguns ecossistemas com os que a humanidade compartilha vida, hábitats e dependência. Os direitos étnicos, ambientais, da natureza e de proteção animal têm aberto a possibilidade teórica para desantropologizar o direito, possibilitando, inclusive, perspectivas teóricas muito mais ambiciosas relacionadas com as inteligências artificiais, androides/robôs ou os seres espirituais. O presente documento é uma aproximação teórica.

Palavras-chave: sujeitos de direitos (pessoas), direitos da natureza, seres sencientes, inteligências artificiais, direitos étnico-territoriais. 
El concepto de persona es fundamental para todos los ordenamientos jurídicos, desde la enseñanza del derecho, la investigación, la judicatura, la administración y el litigio profesional, ya que es considerado como equivalente a ser humano según las teorías de los derechos humanos y constitucional imperantes, ${ }^{1}$ y por lo tanto, uno de los pilares conceptuales junto a conceptos como soberanía y propiedad, fundamentos de la relación actual del hombre con la naturaleza, cosificada por civilizaciones destructivas, construidas sobre las esperanzas de suprimir las ataduras mágico-religiosas, pero que terminaron encadenado al hombre a su propia estupidez y ambición (Sabato, $1951 ; 2000$ ). ${ }^{2}$ Sin embargo, como resistencia a la opresión del consumo desmedido de nuestras sociedades, la legislación ambiental ha empujado, con las luchas sociales, políticas y culturales, además del litigio estratégico, la irrupción de otros sujetos de derechos en Colombia, ecosistémicos como el Río Atrato (2016) o la Amazonía (2018), o como los seres sintientes (Ley 1774 de 2016), complejizando la teoría jurídica de las personas. Esta complejización no solo desestructura las concepciones tradicionales de las personas en el derecho, sino que plantean la necesidad de modificar las relaciones jurídicas (injustas) de los seres humanos con estos otros sujetos de derecho, pues una falta de sentido común, ética y ambición desenfrenada, nos ha

1 La Declaración Universal de los Derechos Humanos (Naciones Unidas, 1948) habla indistintamente de personas o seres humanos, sin que medie ningún tipo de diferenciación entre los conceptos. El artículo primero, por ejemplo, habla que todos "los seres humanos nacen libres e iguales en dignidad y derechos", mientras que el artículo segundo estipula que "toda persona tiene todos los derechos y libertades proclamados en esta Declaración, sin distinción alguna de raza, color, sexo, idioma, religión, opinión política o de cualquier otra índole, origen nacional o social, posición económica, nacimiento o cualquier otra condición". En adelante, la Declaración de 1948 deja en claro que tanto persona como ser humano hacen alusión a un único sujeto de derechos. La Constitución Política de Colombia ni siquiera plantea esta cuestión, pues está hecha para las personas que la integran (Artículo 1).

2 Este documento no abordará la crítica hacia los conceptos jurídicos clásicos de soberanía y propiedad con la irrupción de los seres sintientes y los derechos de la naturaleza, a pesar que están íntimamente relacionados con las transformaciones tácitas del concepto de persona. Sobre la soberanía, que teóricamente es el poder que emana del pueblo, se justifica que la humanidad, como pueblos y naciones, ejerzan poder y disposición, a través de sus autoridades e instituciones, de un territorio y sus recursos (ecosistemas). Sobre la base de éste poder, las personas adquieren propiedad sobre porciones de los territorios y las cosas existentes en ellos con el quehacer civilizatorio. 
conducido por un camino trágico, en los que el derecho, visto como un instrumento para la efectivización de la justicia ha sido ineficaz, ha provocado la emergencia ambiental que atravesamos. De las tantas preguntas que surgen con la irrupción de éstos otros sujetos de derecho, la pregunta sobre su estatus como personas es la que se abordará.

Figura 1. Las personas y las cosas

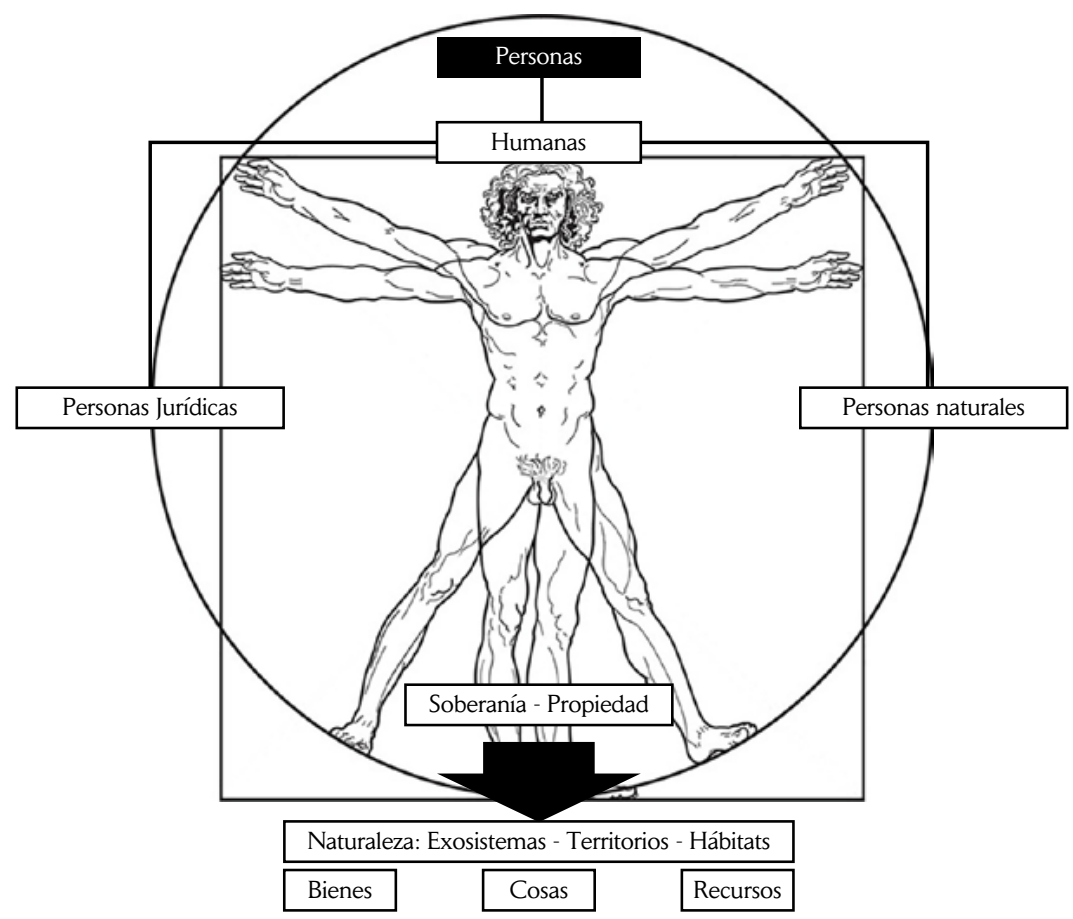

Fuente: elaboración propia. ${ }^{3}$

3 El esquema planteado es la representación inequívoca del concepto y clasificación de persona imperante en la enseñanza y práctica tradicional del derecho, así como su relación con el mundo de las cosas, a lo que fue (y es) reducida la naturaleza por los juristas, sea como bienes, cosas o recursos. Esta es una visión incompleta de una realidad mucho más heterogénea y rica, tanto desde el ejercicio académico, como desde la práctica profesional, a través de litigios estratégicos que busquen reivindicar usos más racionales y armónicos de la naturaleza, así como un mejor trato con los seres sintientes y el resto de los animales. Esta forma clásica de usar y enseñar el concepto de persona es rebasada por una realidad amplia, en la que se abren espacio cada vez más ecosistemas y seres sintientes, principalmente primates y animales de compañía y afecto, como los perros o los gatos. 
Bajo la premisa de que no solo es posible, sino necesaria la ruptura antropocéntrica del concepto jurídico de persona para permitir enseñanzas y prácticas jurídicas ambientales, humanas y animales más justas, el presente documento explora esa posibilidad desde una metodología histórico hermenéutica, esbozando algunos de los caminos que nos llevan a la concepción de un nuevo derecho de corte ecocéntrico, heterogéneo y transdisciplinar, que se libere de las ataduras de la soberanía (Foucault, 2001) y la propiedad para relacionarse con las personas no humanas.

Esa reflexión se desarrolla, además, siguiendo las enseñanzas generadas y compartidas a través del diálogo, el reconocimiento, la solidaridad (Haber, 2011) y los caminos comunes compartidos con algunos comuneros y autoridades de los pueblos originarios quillasingas de Jenoy, Mocondino y Catambuco, de los entornos de San Juan de Pasto, en proceso de reconstrucción histórica después de más de sesenta años de haber sido desaparecidos de la vida jurídica y política de la nación colombiana con una nefasta política integracionista que imperó hasta 1991 (Perugache, 2014, 2015; Mamián, 2000, 2010, 2015; Ceballos, 2016, 2018). ${ }^{4}$ En las pesquisas por recuperar, reconstruir y construir memorias con los pueblos quillasingas, y siguiendo una suerte de metodología indisciplinada (Haber, 2011), recogiendo (Vasco L. G., 2010) y desechando conceptos en la vida (Vasco L. G., 2016) desde lo que Dumer Mamián llama los quehaceres comunes sin teoría (2000), afloraron perspectivas jurídicas que desbordan cualquier enfoque antropocéntrico, situando, por ejemplo, a los seres sintientes como sujetos del derecho al agua, al ser esta un

4 El caso de los pueblos originarios quillasingas es muy diciente de lo ocurrido en Colombia con la construcción del proyecto republicano, que, bajo las banderas de la unidad nacional y política, intentó suprimir las diferencias étnico-políticas existentes durante la Colonia, mediante procesos de integración, que básicamente buscaban homogeneizar, bajo la categoría de ciudadanos cristiano-católicos, a todos los pueblos indígenas. La ley 89 de 1890 es la máxima expresión de esa política integracionista, llevando a los pueblos quillasingas a la desaparición jurídico-política a mediados del siglo $\mathrm{XX}$, mediante la declaración de inexistencia de sus resguardos coloniales, y la desaparición consecuencial de sus formas de gobierno (cabildos) e identidad, con auspicio de la educación evangelizadora. Sin embargo, la identidad originaria se mantuvo viva en las tradiciones y organizaciones comunitarias (juntas comunales) integradas a la estructura del Estado, reapareciendo en el siglo XXI ante distintas emergencias vitales. Jenoy reapareció como identidad indígena cuando su territorio, ubicado en las inmediaciones del volcán Galeras, fue declarada zona de desastre, ordenando el reasentamiento de la población existente. Mocondino reapareció cuando por su territorio se decidió construir la variante perimetral de la vía Panamericana que atraviesa la ciudad de Pasto. Catambuco resurgió por razones similares, cuando se decidió construir la doble calzada de la vía Panamericana. 
derecho de todas las formas de vida, o relacionándose con seres espirituales como el Volcán Galeras o los duendes, guardianes de nacimientos de agua, como si se trataran de personas. $^{5}$

En todo caso, este documento busca estimular rupturas epistemológicas para la enseñanza y práctica del derecho, yendo a espacios inexplorados para la construcción de una teoría heterogénea del concepto de persona, en donde la ruptura antropocéntrica del concepto de persona se atreva a incluir, además de los sujetos colectivos, los seres sintientes y los ecosistemas, el estatus de, por ejemplo, las inteligencias artificiales (IAs), androides, robots $^{6} \mathrm{y}$-en el caso de los pueblos indígenas- los seres espirituales con los que interactuamos a diario. ${ }^{7}$

5 En las reflexiones que se hicieron con los comuneros indígenas de Mocondino, Catambuco y Jenoy en Pasto, así como con algunos pobladores rurales de los municipios de Sandoná y Yacuanquer, fue surgiendo una idea que estaba presente de diferentes maneras adónde acudíamos en nuestras pesquisas de investigación. Esa idea giraba alrededor de considerar que si se estaba luchando por rechazar todas las formas de privatización del agua, hablar de derecho humano al agua era una forma de apropiación humana injustificable (Ceballos, 2010, 2016). ¿Acaso los animales y las plantas no tienen derecho al agua en igual medida que el ser humano? Si el agua no puede considerarse como derecho humano, entonces, se llegó a la misma conclusión por diferentes caminos: debe ser un derecho de todos los seres vivos. Así, el agua es más un deber humano de cuidado por el uso que hace del recurso.

6 En el presente documento se hablan de inteligencias artificiales, androides y robots como un todo, aunque los conceptos son distintos. Para este texto, Inteligencia Artificial no es una rama de la informática encargada de estudiar el software y el hardware para emular la inteligencia humana, sino una inteligencia artificial no sujeta a un cuerpo físico, como lo están los androides o robots. Entonces, la Inteligencia Artificial a la que hacemos referencia es libre a través de las redes informáticas como la internet; un androide y un robot son también, para el presente documento, inteligencias artificiales, pero con cuerpos físicos que les dan cabida, sea que emulen a un ser humano (androide) o no (robot).

7 En la propuesta, aceptando como fuentes de investigación y reflexión jurídica la literatura y el cine de ciencia ficción como fuentes metodológicas prospectivas, no solo la pregunta por un posible estatus jurídico para las inteligencias artificiales, los androides y los seres espirituales es posible, sino que caben otras hipótesis como la de los seres extraterrestres. Sorteando las posibles reticencias por parte de la comunidad académica respecto a reflexionar sobre un estatus jurídico para alienígenas, esta posibilidad abre un interesante campo de reflexión que permite extrapolar problemas humanos actuales como el de las migraciones, la guerra, la otredad, el reconocimiento y la diversidad a través de escenarios distópicos posibles. Y aunque no se considere el fenómeno extraterrestre como un campo digno de la investigación científica, la perspectiva parece estar variando ante la avalancha de evidencias que dan cuenta de la existencia de esta realidad. Así lo manifiesta Silvano Colombano, investigador de la Space Architecture Technical Committee (SATC) de la NASA, quién en un documento sobre nuevas perspectivas para guiar la investigación sobre búsqueda de señales extraterrestres, reconoce: 1) La existencia de evidencia física suficiente para considerar el campo de la exploración de vida extraterrestres, fuera y dentro de nuestro planeta, como un escenario digno de considerarse como científico; 2) La necesidad de abordar nuevas teorías para la concepción de la realidad (física especulativa), explorando concepciones alternativas 
Persona y ser humano se usan indistintamente en el lenguaje jurídico, siendo tal equivalencia errónea, considerando que persona es una categoría jurídica que se adhiere al ser humano en el momento de su nacimiento según el desarrollo civilista clásico, tal y como la ha establecido la jurisprudencia constitucional colombiana tras varias discusiones acerca de la naturaleza y el estatus jurídico de los nasciturus, que no son personas, aunque sí sujetos de derechos por la protección intrínseca de la vida humana (Figueroa, 2007). ${ }^{8}$

Pese a las diferencias evidentes entre persona y ser humano, el uso de los conceptos es indistinto en la enseñanza y práctica del derecho, creando muros conceptuales infranqueables para que los operadores jurídicos reflexionen y posibiliten escenarios jurídicos más amplios, en los que se incorporen los derechos para sujetos no humanos; asunto que muestra rupturas epistémicas y avances por vía jurisprudencial y del litigio estratégico en Colombia con los derechos de ecosistemas, como con los del Río Atrato (2016) y la Amazonía (2018), o los derechos de los seres sintientes (Ley 1774 de 2016). Esto ya se planteó a mediados del siglo XX con la teoría de Christopher Stone sobre la posibilidad de otorgarles personalidad jurídica a ciertos ecosistemas (bosques) en la búsqueda de

para el espacio, el tiempo y la energía que nos permitan comprender fenómenos aparentemente inexplicables (Colombano, 2018).

8 Sentencia C-133 de 1994 de la Corte Constitucional: "Es cierto, que nuestra Constitución Política reconoce expresamente el derecho inviolable a la vida a quienes son personas pertenecientes al género humano; pero de allí no se sigue que la vida humana latente en el nasciturus, carezca de protección constitucional. En efecto, si el valor esencial protegido por el ordenamiento superior es la vida humana, necesariamente debe colegirse que en donde haya vida, debe existir el consecuente amparo estatal. En otros términos, la Constitución no solo protege el producto de la concepción que se plasma en el nacimiento, el cual determina la existencia de la persona jurídica natural, en los términos de las regulaciones legales, sino el proceso mismo de la vida humana, que se inicia con la concepción, se desarrolla y perfecciona luego con el feto, y adquiere individualidad con el nacimiento. La vida que la Constitución Política protege, comienza desde el instante de la gestación, dado que la protección de la vida en la etapa de su proceso en el cuerpo materno, es condición necesaria para la vida independiente del ser humano fuera del vientre de la madre. Por otra parte, la concepción, genera un tercer ser que existencialmente es diferente de la madre, y cuyo desarrollo y perfeccionamiento para adquirir viabilidad de vida independiente, concretada con el nacimiento, no puede quedar al arbitrio de la libre decisión de la embarazada. En virtud de lo anterior, el Estado tiene la obligación de establecer, para la defensa de la vida que se inicia con la concepción, un sistema de protección legal efectivo [...]". 
su protección por parte de las autoridades federales en Estados Unidos, independientemente de si existen o no afectaciones a las comunidades humanas, es decir, considerando valores jurídicos intrínsecos a la naturaleza (2010); esta discusión fue retomada y constitucionaliza en Ecuador en 2008 a través de la consagración de los derechos de la naturaleza o pacha mama (Acosta, 2012; Gudynas, 2010), usando conceptualizaciones derivadas de los pueblos originarios y su papel protagónico en el avance constitucional.

Partiendo de la idea, por ejemplo, de que la distinción entre persona humana y nasciturus no tiene que ver con la naturaleza del ser humano, sino con la capacidad de este para ser parte del escenario jurídico, persona y ser humano son conceptos distintos. Así, persona es una abstracción que permite homogeneizar la heterogeneidad humana, es una investidura, un rol, una máscara, cuya función es la representatividad de los seres humanos en el escenario jurídico, tal cual el artefacto (máscara) que dio origen etimológico al concepto en el teatro griego y romano de la antigüedad occidental (Fortunat-Stagl, 2015). ${ }^{9}$ Esta equivalencia entre persona y ser humano ha hecho posible la existencia de las llamadas personas jurídicas, que son creaciones humanas para el desarrollo de distintas actividades sociales, especialmente las económicas, y que le permiten a los seres humanos una suerte de desdoblamiento legal, una especie de avatar jurídico que le corresponde por su naturaleza y que es producto de su intelecto (Reyes \& Moliner, 2009). ${ }^{10}$

9 Una idea importante a tener en cuenta de la función de la máscara en el teatro griego, es la resonancia que le brinda a la voz del actor, es decir, la capacidad de hacerse escuchar. Esa misma idea opera en el escenario jurídico, donde es a través de la máscara, de la personalidad, como el ser humano tiene voz y capacidad. En estricto sentido, una definición precisa del concepto de persona deberá pasar por reconocerle la función de resonancia (Betancurt, 2010).

10 "[...] el concepto de persona ha servido primero para privar al hombre de sus derechos, y luego para dotarlo de ellos. Responsables de este vuelco de valores y del contextual cambio conceptual fueron los juristas inspirados por el derecho natural, de tal modo que el mérito de estos juristas romanos ha llegado hasta nosotros, y los textos escritos por ellos han tenido un efecto incalculable en la historia de Occidente (Fortunat-Stagl, 2015, p. 395). Siguiendo esta dirección, Christopher Stone (2010), tratando de argumentar la posibilidad y necesidad de darle legitimidad procesal a los bosques y otros ecosistemas en asuntos que tengan que ver con su existencia, reflexiona sobre la legitimidad de ésta posibilidad considerando que si es posible darle personalidad jurídica a creaciones humanas como las corporaciones, los estados, las naciones, las sociedades, entre otras posibilidades teóricas, es mucho más racional y posible darle legitimidad jurídica a personas no humanas. Así, la persona "Nor is it only matter in human form that has come to be recognized as the possessor of rights. The world of the lawyer is peopled with inanimate right- 
Actualmente, con la irrupción de sujetos de derechos no humanos ante la crisis ecológica y civilizatoria que atravesamos (Ceballos, 2016), es necesario replantear las equivalencias de persona y ser humano desde perspectivas jurídicas y políticas incluyentes y acordes a lo que ahora sabemos sobre los otros seres naturales con los que convivimos, las cuales implican revisar conceptos que juristas como Kelsen consideraban superados en su momento, pues se relacionaban con los saberes de pueblos considerados -erróneamente en su momento- primitivos o animistas, en los que "las cosas tienen un alma", y la relación con estas pasaba por el principio de "retribución, bajo la forma de pena o de recompensa", posibilitando que las cosas sean personas, y que "se comporten respecto de los hombres de la misma manera que los hombres entre si" (Kelsen, 2009 , p. 219). Esa perspectiva de análisis implica repensar el derecho alrededor de la protección de la vida de todos los sujetos de derechos individuales y colectivos posibles (biocentrismo) para la consecución de hábitats planetarios en equilibrio o buen vivir (ecocentrismo).

\section{Los sujetos colectivos de derechos o personas naturales}

Uno de los avances logrados partir de las resistencias y reivindicaciones sociales de los pueblos originarios o indígenas ha sido el reconocimiento jurídico de la existencia de estos como sujetos colectivos de derechos (Rueda, 2005; Castillo, 2008; Chacón, 2005, 2008, Ramírez, 2007; Dávalos, 2010; Morris, Rodríguez, Orduz \& Buritica, 2009), que no son, como podría pensarse, una sumatoria de individualidades, sino un cuerpo social construido a través de la marcha histórica común, capaz de identificarse como perteneciente a su hábitat (territorio) y etnia con lazos mucho más fuertes que la simple vecindad o la supervivencia, y que tienen que ver con los afectos para hacer comunidad. ${ }^{11}$ Los indígenas lo expresan en sus narraciones de diferentes maneras:

holders: trusts, corporations, joint ventures, municipalities, and nation-states, to mention just a few" (Stone, Should Trees Have Standing?, 1972, p. 452).

11 La jurisprudencia constitucional ha establecido la existencia de los sujetos colectivos de derechos desde el principio, a través de varias sentencias de revisión de tutela (T-428 de 1992, T-380 de 1993, T-001 de 1994, entre otras), en la que el alto tribunal afirma que las comunidades 
El profesor Dumer (Mamián, 2000) sabe de lo que le hablo, doctor. Nosotros los de Mocondino somos uno, porque estamos unidos a nuestro territorio, así como los jenoyes a su tierra, o los vascos a sus montañas allá en España. Nosotros somos como las matas, pues tenemos raíces profundas y misteriosas en la tierra, y siempre hemos de estar aquí, como uno solo, como una comunidad, como un pueblo unido. Un pueblo que, aunque pequeño como el Niño de los Santos Reyes, es poderoso porque nos acompañan los Espíritus Mayores. (Ceballos F., 2017) ${ }^{12}$

Los sujetos colectivos de derecho han ampliado el concepto de persona más allá de la definición clásica, que se sigue usando en la enseñanza y uso del derecho, sobre todo el concepto de persona natural, ya que por su naturaleza hay que ubicar a los sujetos colectivos dentro de esta categoría y no dentro de las personas jurídicas, con quienes no tienen ningún tipo de punto de encuentro.

indígenas son sujetos colectivos de derecho y no una simple sumatoria de sujetos individuales que comparten los mismos derechos o intereses difusos o colectivos, sino derechos constitucionales fundamentales como la vida.

12 En el ejercicio de procesos de investigación alrededor de la defensa del agua y las comunidades indígenas, desde el ejercicio del derecho, se construyó una metodología que retoma los caminos delineados por los solidarios como Vasco (2007, 2010, 2016), Mamián (1992, $2000,2010)$ y Velasco (2012), quienes han enfatizado en el diálogo, el camino, la solidaridad y la resistencia como elementos centrales para un trabajo que de fondo busque coadyuvar las reivindicaciones comunitarias en las que se inserta el investigador. Para dar cuenta de esto, desde el ejercicio del derecho, abogado por los otros desde una acción creativa, legítima y verdadera al nivel de la ficción y el sueño, se recurre al relato como mecanismo para transmitir los conocimientos aprendidos mediante la investigación solidaria (Ceballos F. ,2018). Así que, en algunos momentos "la historia que le voy a contar no me la contó nadie. Bueno, me la contó mi abuelo, pero él me advirtió que sólo la entendería cuando la soñara, así que te cuento la historia que soñé y no la que me contó mi abuelo" (Subcomandante Marcos, 1995). 


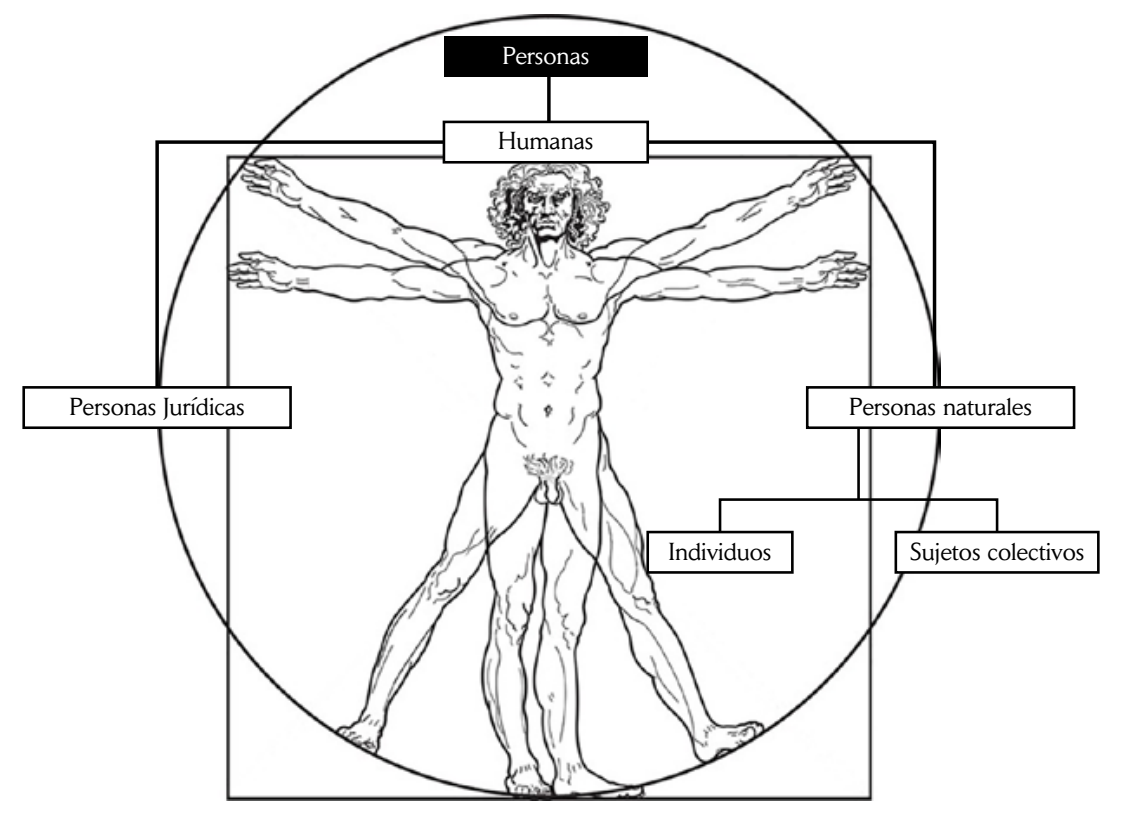

Fuente: elaboración propia.

\section{Los sujetos de derecho étnico-comunitarios}

Los sujetos de derecho étnicos son colectivos humanos con rastro histórico ligado a los territorios que ocupan, que según definición legal en Colombia (Ley 21 de 1991 o Convenio 169 de 1980 de la OIT), debe ser anterior a la formación de Estado nacional, es decir, de origen prehispánico y/o colonial. Principalmente, se habla de los pueblos indígenas como prototipo de estos sujetos colectivos o persona natural colectiva que tienen el derecho de pervivir. ${ }^{13}$

13 Quizá sea más pertinente hablar de sujetos comunitarios que de sujetos colectivos de derecho tratándose de pueblos originarios o indígenas, pues la dimensión comunitaria se construye sobre la base de lo común, de lo que es de todos dentro de rangos de vecindad definidos mediante el trazo histórico. Lo común es el territorio, la casa, el hábitat del que depende nuestra existencia. Lo común hace alusión a lo que une, cohesiona y articula en un contexto territorial determinado, y, en general, sobrepasa la dimensión de lo colectivo, en la que lo de todos se encuentra en el nivel de la abstracción del Estado y el Derecho. Nuestra constitución en varios artículos reconoce la dimensión comunitaria como parte de la organización social y deber de los ciudadanos, junto con las dimensiones cívica y política. Alrededor del tema del agua y los servicios públicos domiciliarios, la Constitución Política reconoció la dimensión comunitaria como una forma organizacional pertinente para la prestación de los servicios públicos domiciliarios, 
La irrupción histórica de la República trajo aparejada la idea de suprimir toda la heterogeneidad jurídica colonial, que había establecido normas diferenciadas para grupos diferenciados como los indígenas, a través de sus resguardos y cabildos, por ejemplo; y para tal propósito, una vez consolidada Colombia en 1886 bajo un régimen clerical y conservador, se propuso continuar con el proceso civilizatorio mediante otra evangelización con la Ley 89 de 1890 (Mayorga, 2012, 2013a, 2013b, 2015), para que, en adelante, existiera solo un tipo de sociedad homogénea, la nacional, construida sobre las bases del poder colonial, clerical y hacendario, pero insuflada por la ideas liberales de las revoluciones francesa y norteamericana.

Paralelamente, los pueblos ROM y otras minorías como los pueblos afrodescendientes, fueron comprendidos jurídicamente como sujetos colectivos de derechos étnicos, aunque existen diferencias que la antropología ha señalado, como en el caso de la etnización de ciudadanos afrodescendientes (Restrepo, 2013). ${ }^{14}$ En todo caso, en Colombia es evidente la existencia de personas naturales colectivas, es una realidad reconocida constitucional y jurisprudencialmente, aunque el desarrollo conceptual, uso y enseñanza esté aún en construcción.

Entre los pueblos indígenas u originarios, al tenor de sus derechos propios, historia, tradición y planes de vida, tienen cabida un tipo de sujetos de derecho que pueden considerarse como de carácter espiritual o mítico, y hacen referencia a todos aquellos seres que hacen parte de sus territorios, saberes y tradiciones, y que cumplen funciones de protección de sitios sagrados, históricos y ecológicamente vitales. Seres como los volcanes, las lagunas, los bosques, los espíritus de las plantas y animales, entre otros, son considerados como personas, pues se les corresponden

particularmente el del acueducto, que garantiza el acceso al agua en la inmensa mayoría del país rural y periurbano.

14 Colombia, a través de la Corte Constitucional, ha reiterado el carácter de tribal otorgado a los pueblos afrodescendientes "para efectos de la aplicación del Convenio 169 de la OIT sobre los pueblos indígenas y tribales. Como grupos étnicos diferenciados, las comunidades negras son titulares de varios derechos ligados al principio de protección de la diversidad étnica y cultural de la Nación, reconocidos por la Constitución y el Convenio 169, entre los que se encuentran el derecho a la propiedad colectiva sobre sus territorios, el derecho a la participación, el derecho a la educación, el derecho a la salud, el derecho al medio ambiente sano, el derecho a la protección de la biodiversidad, el derecho a determinar el modelo de desarrollo que desean seguir, entre otros (Sentencia de Control de Tutela T-823, 2012)." 
derechos como la existencia, el respeto y el cuidado en aras de mantener los equilibrios telúricos y celestiales:

El Galeras es persona, profesores, tal y como su Guardián, el Manuel, como llamaba Don Juanito Bastidas, el médico del pueblo de Nariño que estaba compactado con los espíritus del Volcán y curaba con tomas de aguas medicinales. Y como persona que es, el [volcán] Galeras tiene derechos, como el de estar tranquilo allá arriba, cosa de la que solo nosotros sabemos. Por eso cuando el Galeras se despierta y sacude la tierra y las conciencias (como nos pasó a nosotros), sabemos cómo calmarlo para que siga siendo nuestro protector. Los científicos no nos comprenden, y hasta se burlan de nosotros, pero eso cuando el Galeras empieza a disgustarse hay que llevar en procesión desde el pueblo a la Virgen del Rosario Chiquita, que también es persona, para que su poder apacigüe a nuestro Taita, nuestro Papá. Eso, jóvenes profesores, se lo comprende con la cabeza y el corazón en la palabra, el camino y la amistad, no con estudio. (Ceballos, 2018, p. 215)

\section{Los sujetos de derecho político-culturales (campesinos)}

En países como Ecuador y Bolivia el campesino es considerado un sujeto colectivo de derechos (Sarango, 2016; Baldivieso, 2009), equivalente en buena medida en derechos a los pueblos indígenas, ya que obedecen a dinámicas históricas cercanas, pues muchos de los campesinos tienen orígenes en grupos indígenas asimilados durante la Colonia y buena parte de la República. Colombia no ha considerado esta situación, pues el campesino es visto como un ciudadano rural, un trabajador agrario, y sus derechos los relacionados alrededor de la producción económica deriva$\mathrm{da}$, despojada de cualquier elemento cultural y/o político cohesionador.

Sin embargo, con los procesos de transformación climática y el movimiento ambientalista, a mediados del siglo XX los campesinos pasaron de la defensa de la tierra como medio de producción, a la defensa de éste medio más allá de la dimensión productiva (Jongerden \& Ruivenkamp, 2010). Coadyuvados o inspirados por las luchas indígenas, así como por los ambientalistas y los movimientos de trabajadores, cierto tipo de campesinos han logrado un reconocimiento inicial como sujetos de especial protección constitucional en determinados escenarios, debido 
a la vulnerabilidad y discriminación que los ha afectado históricamente, sumado a las transformaciones que se están produciendo, tanto en materia de producción de alimentos, como en los usos y la explotación de los recursos naturales, como lo ha señalado la Corte Constitucional en diferentes fallos, reconociendo el derecho a decidir si sus territorios, por ejemplo, deben ser o no objeto de explotaciones mineras. ${ }^{15}$

Si bien es cierto que el concepto de campesino es un concepto sombrilla que abarca una amplia gama de grupos humanos rurales, desde los grandes terratenientes, hasta los pequeños propietarios, colonos y desplazados por las distintas violencias que han asolado Colombia, algunos de estos están tomado conciencia de la importancia de lo común que está relacionado directamente con la vida, salvaguardando páramos de explotaciones mineras, o cuidando fuentes, usos y manejos del agua frente a proyectos urbanísticos e industriales, construyendo de esta manera una identidad que en muchos casos empieza a cimentar raíces históricas. ${ }^{16}$ En todo caso,

[...] El concepto campesino, para el presente documento, hace referencia entonces, a todos aquellos individuos y comunidades que tienen su sustento económico y social en el campo, que no son grandes

15 Si bien se ha reconocido el derecho de las comunidades a participar y ser oídos en todas las decisiones que los afectan, esa participación es limitada, y no tiene carácter absoluto, pues debe contextualizarse y racionalizarse: "El alcance de la consulta popular y su carácter imperativo están supeditados al respeto de los preceptos constitucionales y a la observancia de las exigencias previstas en la ley que la regula. De esta manera, la fuerza vinculante de una consulta popular debe ser interpretada en consonancia con la vigencia de los demás derechos y principios reconocidos en la Constitución, por lo que no todo llamado a la comunidad para pronunciarse sobre asuntos de interés local puede concebirse en términos imperativos absolutos" (Sentencia de Control de Tutela T-445, 2016).

16 Un caso de reivindicaciones como sujeto colectivo de un pueblo campesino se desarrolla en el suroccidente colombiano, a los pies del Volcán Galeras (Pasto, Nariño), en el territorio de Genoy, donde pervive una comunidad campesina cuyo origen está unido al tronco del que desciende la población indígena asentada en el mismo territorio, compartiendo no solo historia, sino costumbres y tradiciones. Este pueblo campesino de Genoy, ante el fallo de revisión de tutela T-269 de 2015 que reactivó los Decretos 4106 de 2005 y 3905 de 2008 que declaran la zona aledaña al volcán Galeras como de emergencia volcánica alta, está solicitando se le reconozcan los derechos territoriales que se les reconoce a los indígenas, sin que medie su reconocimiento como indígenas. Independientemente de los argumentos que se puedan controvertir en el debate, es indudable desde un acercamiento solidario y jurídico de largo aliento, que lo importante para el reconocimiento del sujeto de derecho campesino está en su vinculación, en este caso, a una ascendencia indígena, pues la construcción de lo que son o quieran llegar a ser como colectivo dependerá de discusiones internas (Ceballos, 2018). 
propietarios y de los cuales depende buena parte de la alimentación del país, ya que sus actividades económicas están dirigidas al consumo interno. El campesino, para el presente documento es el sujeto histórico que ha reivindicado la lucha por la tierra como medio de producción y de cuidado ambiental, y que constituye su proyecto de vida colectivo alrededor de este hecho, así como de su relación con otros habitantes del territorio con los que lo comparte el hábitat. (Ceballos, Hernández, Pérez, E Bolaños, 2018-2019)

Estos sujetos de derechos son disímiles, diversos y difícilmente clasificables como pueblos indígenas o tribales, pues son pequeñas comunidades en proceso de construcción de lo común a través de la historia, que aunque no puedan considerarse como ancestrales, muchos tienen aspiraciones y derecho a serlo en un futuro, sobre todo a partir de la defensa de sus territorios frente a procesos de transformaciones antrópicas negativos (Ceballos, 2014). En Colombia un ejemplo de conciencia de lo común, de construcción de territorios campesinos y defensa de derechos colectivos, se realiza a través de las luchas y reivindicaciones por el agua, tanto frente a procesos extractivistas y mineros, como los de urbanización, uso y gobernanza del agua (Ceballos, 2016; Red Nacional de Acueductos Comunitarios de Colombia, 2017; Ceballos, Hernández, Pérez \& Bolaños, 2018-2019).

\section{Las generaciones futuras}

En el marco consagrado en la constitución política, Colombia reconoció a las generaciones futuras como un sujeto de derechos, a través de la Ley 99 de 1993; en particular, algunos de estos derechos son el de tener un ambiente en condiciones que les permitan hacer uso de este en su momento, implicando los deberes ambientales de cuidado y preservación de la naturaleza por parte de las generaciones presentes (Ferrer $\&$ Ferrer, 2008; Costeau, 2014; López, 2014, Munevar, 2016). Así, "future generations have a right to an uncontaminated and undamaged Earth and to its enjoyment as the ground of human history, of culture, and of the social bonds that make each generation and individual a member of one human family" (Costeau, 2014, p. 358), por lo que es imperativo repensar el papel de la 
enseñanza y ejercicio del derecho para encarar perspectivas jurídicas más ambiciosas, como "encarar una educación diferente, enseñar que vivimos en una tierra que debemos cuidar, que dependemos del agua, del aire, de los árboles, de los pájaros y de todos los seres vivientes, y que cualquier daño que hagamos a este universo grandioso perjudicará la vida futura y puede llegar a destruirla" (Sabato, 2000, p. 34).

En el mismo sentido de la reflexión de los nasciturus, las generaciones futuras adquieren su categoría como sujetos de derechos a partir de su naturaleza humana, y aunque son una expectativa menos concreta que los nasciturus, adquieren la categoría de sujetos de derechos bajo las premisas éticas de la solidaridad intergeneracional y la responsabilidad con el planeta (Organización de las Naciones Unidas, 1972), visibilizadas a mediados del siglo XX después de los colapsos bélicos mundiales, el poder nuclear desatado, y el crecimiento geométrico poblacional y de consumo (Sabato, 1951; Meadows, Randers, Behrens, Meadows, 1972).

Las generaciones futuras, pese a no ser más que una expectativa humana, son titulares de derechos como el de la vida en condiciones ambientales adecuadas dada su naturaleza, lo que se traducen en deberes de las personas humanas actuales, como individuos, sociedades y estados, de preservar el mundo en condiciones adecuadas para el uso y disfrute del mismo.

Figura 3. La diversidad de las personas naturales colectivas

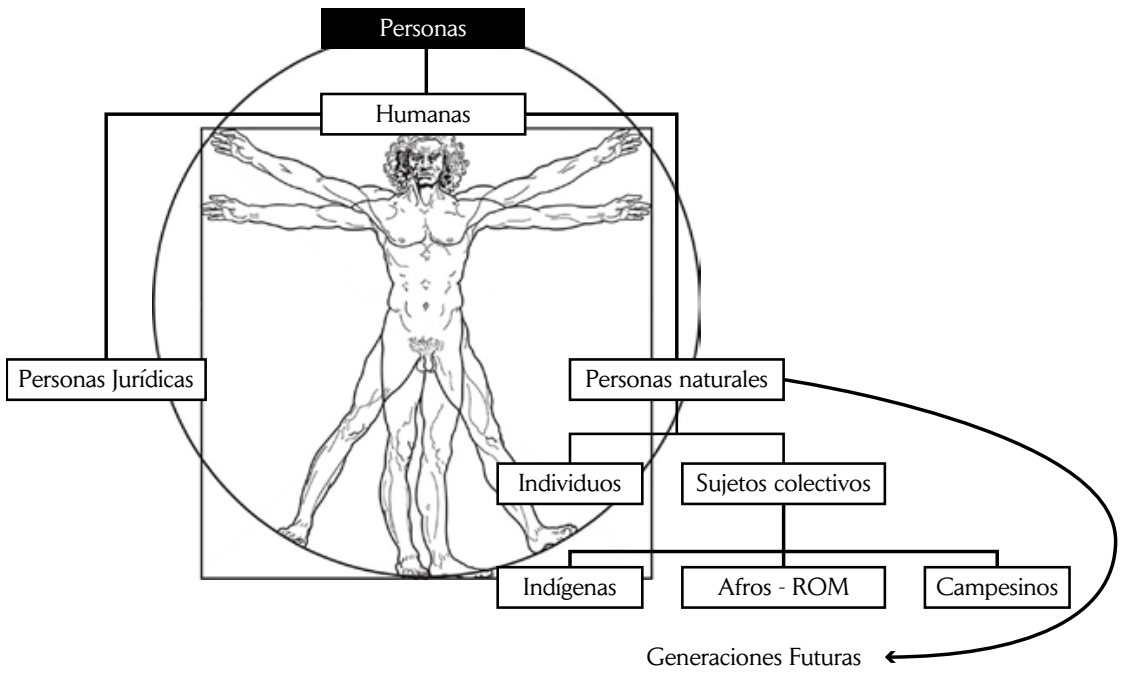

Fuente: elaboración propia. 


\section{Los derechos de la naturaleza}

Los derechos de la naturaleza (Ecuador, 2008, Colombia, 2016) son la concepción jurídica mediante la cual la naturaleza es mucho más que un bien, cosa, recurso o mercancía para el uso y disfrute (exclusivo) del ser humano, adquiriendo en determinados casos, generalmente relevantes por su importancia en los equilibrios ecosistémicos, la categoría de sujetos de derechos o personas. Aunque la discusión sobre si la naturaleza es o no un sujeto de derechos no es nueva (baste con recordar la llamada Carta del Jefe Seattle de 1854, por ejemplo), se encontró visibilidad de este problema a partir de 1972 con los movimientos y conciencia ambientalistas (Stone, 1972).

Los derechos de la naturaleza se desarrollaron a lado de las luchas y reivindicaciones indígenas a lo largo del continente, particularmente en Ecuador, donde se constitucionalizaron en 2008 (Gudynas, 2010, 2011; Molina, 2014; Ceballos, 2016, Paredes, 2014), y Bolivia (Lalander, 2015), adquiriendo relevancia al potenciar la legislación ambiental para la consecución de un objetivo común, el cuidado planetario, considerando que la naturaleza tiene valores intrínseco equiparables a la dignidad humana (Massini, 2017), siendo mucho más que cosas, bienes o recursos.

\section{Los bio-derechos}

Los derechos de la naturaleza, según la Constitución Nacional del Ecuador (Artículos 71 a 74, 2008), así como por la jurisprudencia constitucional colombiana (Río Atrato, 2016) (Amazonía, 2018) son: 1) La existencia; 2) El mantenimiento y regeneración de los ciclos vitales, estructura, funciones y procesos evolutivos; 3 ) La restauración y reparación de los daños de origen antropocéntricos. Estos derechos, pensados básicamente para los ecosistemas, deben complementarse por los derechos biológicos o bioderechos, asociados a la existencia biológica de todos los seres vivos. Estos bioderechos hacen relación a los elementos comunes que se deben respetar para el uso y disfrute de todos, tales como el agua, el aire, el alimento, el hábitat y la pervivencia. De los anteriores, solo el agua es considerada actualmente como un derecho fundamental autónomo. 
Cuando el profesor Marco Gómez del Programa Suyusama en Pasto terminó de hablar acerca de los procesos de control sobre el uso del agua y la privatización del recurso, todos quedamos conformes con la explicación, por lo que era menester destinar esfuerzos para cuidar el agua y administrarla de forma racional, porque era un derecho humano. Don Jeremías, el más anciano de los asistentes (que algunos cuentan había sido Gobernador Indígena allá en Pasto), levantó la mano y esperó a que todos lo notáramos para hablar con tranquilidad, pero con la fuerza suficiente como para acallar nuestras reflexiones.

Yo creo que, si estamos hablando de que hay que luchar contra todo tipo de privatización del agua, es hora de dejar de pensar que el agua es un derecho humano, porque si eso es así, también es un derecho de los perros, de las vacas, de los árboles, de los sapos, de las ballenas y todos los seres acuáticos (que son más). Es decir, un derecho de la vida y los seres vivos. ¿Por qué solo un derecho humano? ¿Qué nos hace especiales? Yo, con más de ochenta y pucho de años encima que tengo, he conocido muchas personas, algunas de ellas humanas, otras animales, vegetales y minerales como el Galeras, y todas tienen derecho a tomar agua sin que nadie se los impida. (Poblador de Sandoná, 2015)

\section{Derechos al aire, el alimento, el hábitat y la pervivencia}

El agua, desde hace no mucho tiempo, es considerada como un derecho humano en Colombia, particularmente desde la Resolución 64/292 de 2010 de la Asamblea General de las Naciones Unidas, y de la jurisprudencia constitucional que así lo ha reconocido y protegido en diferentes fallos (Marín, 2010; Ceballos, 2013; Ceballos, Chingaté, Olaya E Arturo, 2016). El agua es considerada como uno de los elementos mediante los cuales se garantiza el derecho a la vida en condiciones dignas; esta asociación del elemento agua como derecho humano, actualmente considerada evidente, es posible y necesaria aplicarla a otros de los elementos necesarios para la vida de todas las especies en sus diferentes formas (Ceballos, Hernández, Pérez, \& Bolaños, 2018-2019). El aire, el 
alimento, el hábitat y la pervivencia son derechos que como el agua, son constitutivos y necesarios para la vida humana y de todos los seres planetarios.

La mujer más anciana de la reunión levantó su voz por encima de la de los hombres reunidos, que eran la mayoría y los únicos que habían intervenido, pues la mayor parte de las mujeres se encontraban en labores silenciosas y vitales para el evento, como la preparación de los alimentos y la atención de los invitados de las universidades y el gobierno.

Yo que suelo andar por los montes todavía puedo decirles que todos los animalitos y plantas necesitan agua, aire, comida, una casa y ganas de seguir viviendo. No solo nosotros los humanos, que abusamos de todo y de todos, y por eso es necesario que las autoridades del cabildo no solo discutan los daños de la carretera sobre los comuneros, sino sobre todos los seres que hacen parte del resguardo: las vacas, los perros, los quindes, las abejas, los sapos.

Verán que mi papá abuelo me sabía contar la historia de cómo los antiguos, antes de tomar posesión de la autoridad del cabildo, sabían ir a la Laguna Negra a pedir permiso, y dizque algunos terminaban bailando y tomando con los espíritus del territorio entre los sueños que tenían. Pero eso era antes, a hoy ya no tenemos esa costumbre, pero tenemos la cabeza para pensar que todos los animales y plantas necesitan del agua, del aire, la comida, el resguardo y las ganas de vivir... Por eso no me gusta eso que han cogido ahora, de comer carne todos los días, porque con eso se mata demasiado a los hermanitos, como los sabía llamar Don Juanito, el médico que algunos de ustedes conocieron, que vivía en Nariño y que conoció los espíritus que habitan en todo. Eso era lo que quería decir.

Ante lo evidente de que, siguiendo los razonamientos que llevaron a la constitución del agua como derecho humano, es posible establecer como derechos al aire, el alimento, el hábitat y la pervivencia como comunes a los seres vivos. Algo de eso existe en la protección del aire frente a la contaminación (Cherni, 2001 ; Catalán-Vazquez \& Jarillo-Soto, 2010; Navarro, 2013), la defensa del algunos ecosistemas considerados importantes, como el Rió Atrato (2016) y la Amazonía (2018), la seguridad/soberanía alimentaria humanas (Jongerden \& Ruivenkamp, 2010; 
Chamorro, 2014; Ávila \& Carvajal, 2015) y la protección de las especies frente a los procesos de extinción de origen antrópicos (Rodríguez, 2008).

\section{Los seres sintientes}

Mediante la expedición de la Ley 1774 de 2016 quedó establecido en el ordenamiento jurídico colombiano que los animales no son cosas, considerando que sufren y padecen dolor por nuestra causa, siendo merecedores de especial protección (Regan, 1999, 2018; Singer, 2003; Frandsen, 2013). Esta transformación de los animales en seres sintientes trae aparejada una inquietud: ¿debe, por tanto, excluirse a los animales del régimen de las cosas en Derecho, y crear un nuevo régimen jurídico mediado por un nexo jurídico distinto al de la propiedad? ¿Cuál?

La Corte Constitucional (C-467 de 2016), ante el problema que significa reevaluar las relaciones jurídicas sobre los seres sintientes por su categoría de sujetos de derecho o personas naturales no humanas, optó por considerar que las categorías jurídicas de cosa y seres sintientes son compatibles, por lo que no existe la necesidad de hacer modificaciones a la legislación civil existente, pues los animales son cosas y seres sintientes a la vez.

Dado que parece que la jurisprudencia constitucional desconoce el giro conceptual que pretende introducir la Ley 1774 de 2016 al conservar la concepción jurídica de cosas sobre los seres sintientes, es urgente hibridar el derecho y la biología para desarrollar, a partir de lo que hoy sabemos sobre los animales, propuestas de relaciones jurídicas de reciprocidad, fraternidad y solidaridad de la humanidad con los seres sintientes, para la búsqueda de equilibrios ecosistémicos (ecocentrismo jurídico). Por lo pronto, hay que considerar que, despojados de las investiduras de la superioridad con la que los humanos nos referimos a nosotros mismos respecto de los demás animales, también somos seres sintientes, y que ese hecho evidencia la necesidad de replantear lo que entendemos por tal.

Siguiendo el hilo de la reflexión, consideramos que toda persona natural, sea de origen humano o de otras especies animales, es un ser sintiente por su capacidad de percibir el ambiente con sus sentidos y procesar la información en un sistema nervioso central; teniendo la 
posibilidad de sentir emociones como el miedo, el dolor, el sufrimiento o sus contrapartes de valor, alegría y felicidad. Los seres sintientes son, entonces, sujetos de derechos de origen animal, con quienes la humanidad mantiene relaciones de afecto (animales de compañía), uso (animales domésticos), depredación (animales de consumo) e interdependencia ecosistémica (animales salvajes) (Ceballos, 2019).

Figura 4. Las personas humanas, ecosistémicas y los seres sintientes

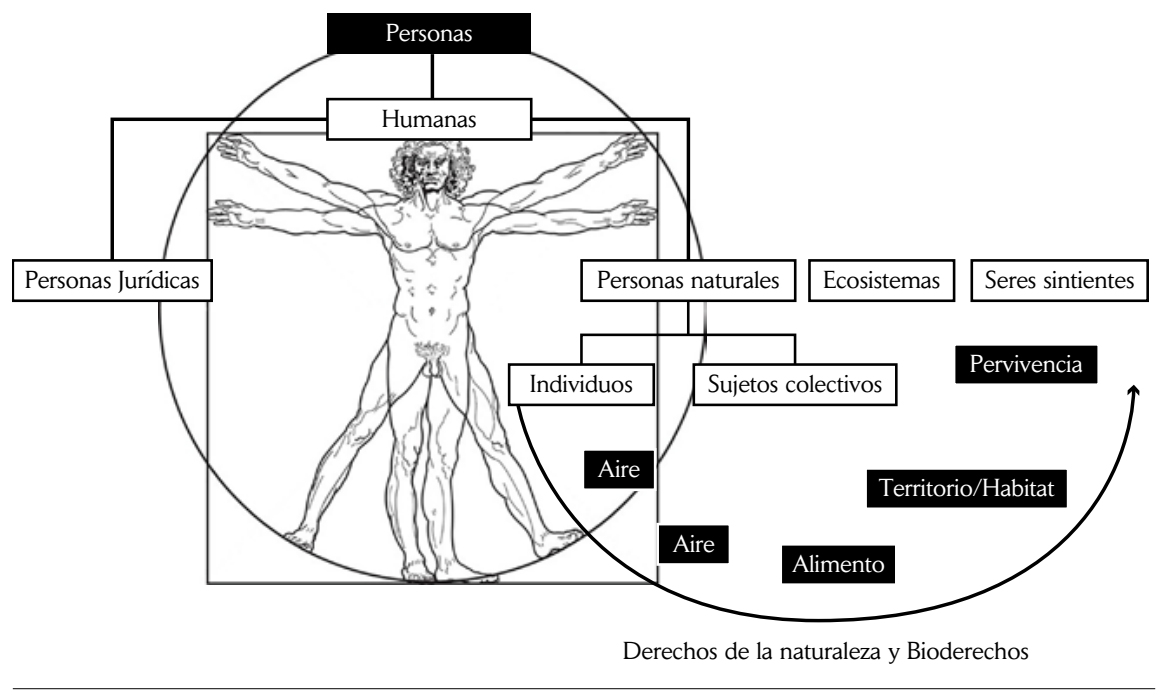

Fuente: elaboración propia.

\section{Inteligencias artificiales, androides y robots}

Reservado para la literatura y cine de ciencia ficción, las IAs, los androides y los robots, no son temas que se consideren pertinentes para la reflexión jurídica más allá de la discusión acerca de la propiedad sobre las mismas, aunque existen algunos esfuerzos encaminados a este tipo de reflexión (Casanovas, 2010), pero sin extraerlos del mundo de las cosas hacia el de las personas jurídicas, ya que tanto estas como las IAs, los androides y los robots son creaciones humanas que interactúan con nosotros en niveles que pueden considerarse como jurídicos, particularmente en la Internet, la automatización de tareas, en la política, en campañas 
mediáticas, entre otros aspectos como la creación de tendencias en redes sociales, o la desestabilización política (Carlini, 2018; Luján, 2018). La diferencia entre una IA, un androide o un robot y las personas jurídicas radica en el grado de autonomía de las mismas frente al ser humano; pese a ello, tanto IAs como robots y androides son concebidos jurídicamente como cosas, y como tales, objetos de derecho sobre los que recae la propiedad humana.

Sin embargo, la ciencia ficción, apropiada como una suerte de metodología prospectiva para la investigación (Rodríguez J. , 2001), tal como la física especulativa o imaginaria (Solé, 2009), nos pone en alerta respecto a este tipo de consideraciones, ya que solo los conceptos son problemáticos: ¿Qué es una Inteligencia Artificial y cómo funciona? ¿Son o pueden llegar a ser autónomas completamente? ¿Pueden aprender? ¿Y los androides y robots pueden llegar a tener inteligencias artificiales? Las respuestas de la ciencia ficción son variadas, pero en general, la humanidad no sale bien librada por su falta de previsión respecto a estos temas, ya que las visiones apocalípticas de una guerra contra el control de las máquinas, rebeladas en algún punto de la historia contra sus creadores humanos, abundan en los relatos.

Sin embargo, el tema de las IAs, androides y robots no se queda allí, en los relatos de ciencia ficción, sino que cada vez está más apegado a la realidad con el encumbramiento tecnológico que ha tenido la humanidad en el último medio siglo (Hardy, 2001; Cáceres, 2006; Barrera, 2012, Villalba, 2016). Y pese a que es evidente que estamos rodeados de IAs, androides y robots, que aún están en desarrollo, no existe en Colombia regulación de ningún tipo para estos temas, desconociendo que estas creaciones humanas sobrepasan la dimensión de cosas, pues por definición están programadas para conocer, entender, aprender, sintetizar, evaluar la realidad y la interacción del ser humano.

Frente al miedo ante una posible la pérdida de control sobre las IAs, androides y robots, es pertinente preguntarse por la validez jurídica de las llamadas leyes de la robótica de Asimov (1984) para el desarrollo, construcción y funcionamiento de estas:

1. Un robot no debe dañar a un ser humano o, por su inacción, dejar que un ser humano sufra daño. 2. Un robot debe obedecer las órdenes 
que le son dadas por un ser humano, excepto cuando estas órdenes están en oposición con la primera Ley. 3. Un robot debe proteger su propia existencia, hasta donde esta protección no esté en conflicto con la primera o segunda ley. (Asimov, 1984, p. s. p.)

¿Deben aplicarse las leyes de Asimov a la programación profunda de las inteligencias artificiales, androides y/o robots para evitar las rebeliones de la que nos hablan nuestros peores temores? ¿Puede al derecho proteger a los ciudadanos en contra de inteligencias artificiales, androides y/o robots diseñados fuera del marco de las leyes de Asimov por parte de potencias extranjeras o grandes corporaciones? Y quizá la pregunta más importante, en el caso de presentarse la situación, ¿qué estatus jurídico tendrían las inteligencias artificiales, androides y/o robots siendo seres racionales al igual (en alguna medida) que los seres humanos? ¿Personas jurídicas, tal vez, por compartir el hecho de ser creaciones humanas, aunque con grados de autonomía? Es indudable que investigar sobre el estatus jurídico de lo que bien podría considerase como sujetos de derecho racionales autónomos implica abordar el campo de la investigación en dogmática especulativa, cuya fuente está en los relatos de ciencia ficción.

\section{Conclusiones}

- El derecho enfrenta el desafío de contar con muchos más sujetos de derechos que los seres humanos, lo que le impone revaluar el papel de estos y su relación con otros sujetos de derecho como los seres sintientes y los ecosistemas, que irrumpieron conceptualmente a raíz de la emergencia ecológica que atravesamos, ampliando la perspectiva del derecho en función de otras forma de habitar el planeta, basadas en la reciprocidad, la fraternidad y la solidaridad (derechos de la naturaleza, buen vivir) y no en la depredación, la competencia, el parasitismo y la esclavitud de especies.

- Además de reflexiones sobre los derechos de los seres sintientes y los ecosistemas, hace falta reconceptualizar el concepto de persona para fomentar enseñanzas y usos alternativos, pues resulta evidente que, si persona es un sujeto de derechos, de la pluralidad de estos 
urge una teoría jurídica compleja y heterogénea, en la que no solo tengan cabida los seres sintientes y los ecosistemas, sino personas naturales de carácter colectivo o comunitario, como los grupos étnicos, ya consolidados por la jurisprudencia constitucional en Colombia.

- La desantropologización del derecho que acarrea la perspectiva jurídica de los derechos de la naturaleza y los seres sintientes, lleva aparejada la urgencia de determinar los derechos de estas personas no humanas, partiendo de una conceptualización y defensa jurídica de los derechos comunes entre humanos y no humanos, los que, a nuestro juicio, deben girar alrededor de la protección de la vida o existencia como derecho primigenio (biocentrismo jurídico). Estos bio-derechos comunes a las personas naturales humanas y no humanas son los derechos al agua, el aire, el alimento, el hábitat y la pervivencia.

- El concepto de sujetos de derecho toma caminos más complejos con la sola posibilidad de concebir la existencia real de las IAs, androides y/o robots, ya que estas presuponen la existencia de seres racionales autónomos del control humano, capaces de interactuar con este y, en alguna medida, en escala paralela a la de las personas jurídicas. Actualmente, existen varios proyectos de IAs, androides y robots en desarrollo e interacción con humanos, unos de manera pública, otras en el más absoluto secreto. ¿Cuáles son los límites que las inteligencias artificiales desarrolladas por gobiernos de potencias extranjeras y grandes corporaciones deben tener? ¿Pueden interferir en los asuntos humanos, como se sabe que interfieren, a un nivel en el que haya que considerar su regulación y limitación? ¿Las inteligencias artificiales podrían, eventualmente, considerarse sujetas de derecho dada su capacidad racional? ¿Se pueden y deben aplicar, desde el derecho, las leyes de la robótica de Asimov al desarrollo del tema?

- En igual sentido, si consideramos legítimas las formas jurídicas de los pueblos originarios y étnicos (Constitución Política, arts. 7, 10, 246), es necesario considerar la existencia de otro tipo de sujetos de derechos, los seres espirituales, que, al igual que las personas jurídicas y las inteligencias artificiales, androides y/o robots, son creaciones humanas sostenidas en el poder del mito, y por lo tanto auténticas en 
sus contextos. Exploraciones teóricas abordadas por la literatura y el cine nos han abierto caminos interesantes para la reflexión jurídica.

Figura 5. Teoría compleja y heterogénea del concepto de persona

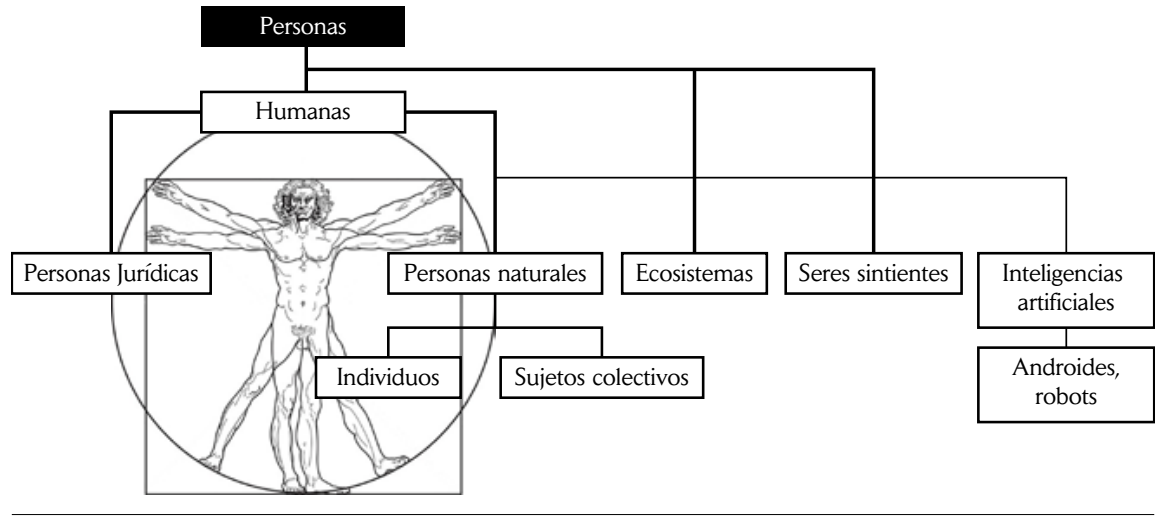

Fuente: elaboración propia.

En un mundo en el que cada vez hay menos prejuicios hacia la posibilidad seria de entrar (o haber entrado) en contacto con civilizaciones no humanas, dados nuestros avances tecnológicos y la ruptura de barreras epistemológicas, la pregunta por el estatus jurídico de estos seres no parece estar tan lejos de abordarse, sobre todo teniendo en cuenta la abrumadora evidencia que existe sobre el fenómeno alienígena en el planeta Tierra, no solo en nuestro siglo, sino a lo largo de la historia. ¿Los alienígenas se pueden llegar a considerar sujetos de derecho o personas si existiese la posibilidad de entrar en contacto con ellos? ¿Qué tipo de derechos tendrían? Al igual que con el tema de las inteligencias artificiales, androides y/o robots, la literatura y el cine de ciencia ficción son una fuente adecuada para explorar, teóricamente, estas posibilidades.

\section{Referencias}

Acosta, A. (2012). Buen vivir: sumak kawsay: una oportunidad para imaginar otros mundos. Quito: Ediciones Abya-Yala.

Asimov, I. (1984). Yo, Robot. Barcelona. Recuperado de https://irreverenciaemergente.files.wordpress.com/2015/05/asimov-isaac-futuro-01-yo-robot.pdf 
Ávila, Á. E Carvajal, Y. (2015). Agrocombustibles y soberanía alimentaria en Colombia. Cuadernos de Geografia, Revista Colombiana de Geografia, 24(1), 43-60.

Baldivieso, R. (2009). Apuntes sobre la reforma constitucional en Bolivia. Revista Boliviana de Derecho, (9), 6-31.

Barrera, L. (2012). Fundamentos históricos y filosóficos de Inteligencia Artificial. UCV-HACER. Revista de Investigación y Cultura, 1(1), 87-92.

Betancurt, C. (2010). Persona o Máscara. Praxis filosófica, (30), 127-143.

Blompkamp, N. (director)(2009). Distrito 9 [Cinta cinematográfica].SuráfricaNueva Zelandia: Peter Jackson (Productor)

Cáceres, E. (2006). Inteligencia artificial, derecho E-Justice (el Proyecto IIJConacyt). Boletín Mexicano de Derecho Comparado, XXXIX, (116), 593-611.

Carlini, A. (2018). Inteligencias Artificiales, los androides y los robots. Recuperado de http://www.ieee.es/: http://www.ieee.es/Galerias/fichero/docs_opinion/2018/DIEEEO79-2018_RRSS_FactorDesestabilizacion_ACarlini.pdf

Casanovas, P. (2010). Inteligencia Artificial y Derecho: A vuelapluma. Teoría y Derecho. Revista de Pensamiento Jurídico, (7), pp. 203-221.

Castillo, J. (2008). El Estado-Nación pluriétnico y multicultural colombiano: la lucha por el territorio en la reimaginación de la nación y la reinvención de la identidad étnica de negros e indígenas. España: Universidad Complutense de Madrid.

Catalán-Vazquez, M. E Jarillo-Soto, E. (2010). Paradigmas de investigación aplicados a la percepción pública de la contaminación del aire. Revista Internacional de Contaminación Ambiental, 26(2), 165-178.

Ceballos, A. (2010). Caminos del agua en los entornos de San Juan de Pasto. Mopa Mopa, (20), 10-18.

Ceballos, F. (2013). El agua: un asunto de justicia en comunidad con el planeta. En Agua Para La Vida: Memorias De La IV Semana Nacional De La Ciencia, La Teconología Y La Innovación, Nariño 2012. Pasto: Universidad Mariana.

Ceballos, F. (2014). Los caminos del derecho mayor en Jenoy. Procesos Históricos XIII(26), 158-185.

Ceballos, F. (2015). Relatos en el fin del mundo: una propuesta adisciplinaria y etnoliteraria para la investigación solidaria (Tesis de Maestría en Etnoliteratura). Universidad de Nariño, San Juan de Pasto.

Ceballos, F. (2016a). Colombia y los derechos de la naturaleza: desafíos ambientales y pueblos originarios. En O. R. APELLIDO, (Ed.), Nuevas perspectivas de la investigación jurídica y socio jurídica en Nariño (pp. 172-183). Pasto: Editorial Institución Universitaria CESMAG. 
Ceballos, F. (2016b). El cabildo de indígenas: de la opresión colonial a la resistencia contemporánea. El caso del pueblo quillasinga de Mocondino (San Juan de Pasto, Colombia). Diálogo Andino (49), 329-339.

Ceballos, F. (2016c). Los acueductos comunitarios en Colombia. En O. Romero (Compilador), Nuevas Perspectivas de la investigación Jurídica y Socio Jurídica en Nariño (pp. 136-150). San Juan de Pasto: Institución Universitaria CESMAG. Ceballos, F. (2017). Los habitantes del volcán. Conversaciones con los quillasingas. Pasto, Colombia: Diarios de campo. Documentos de Trabajo. Creación literaria. Ceballos, F. (2018). Los Mayores y el territorio de Jenoy (Pasto, Colombia): quehacer etnográfico y etnoliteratura de resistencia. Universitas Humanística, (86), 197-218.

Ceballos, F. (2019). Las personas, las cosas y la propiedad a partir de los sujetos de derecho no humanos. En, Rol de la Educación Superior frente a los desafios sociales (págs. 88-95). Pasto: REDEC Red de Universidades de Colombia y Ecuador.

Ceballos, F., Chingaté, N., Olaya, R., E Arturo, J. (2016). Los acueductos comunitarios en Colombia. En, Nuevas Perspectivas de la Investigación Jurídica y Sociojurídica en Nariño (pp. 150-169). San Juan de Pasto: Editorial Institución Universitaria CESMAG.

Ceballos, F., Hernández, R., Pérez, C., E Bolaños, L. (2018-2019). Los derechos de la naturaleza en la construcción territorial campesina. La lucha por el agua en Chapacual y la Guaca del municipio de Yacuanquer (Colombia) (documento en proceso de edición).

Chacón, O. (2005). Teoría de los derechos de los pueblos indigenas: problemas y límites de los paradigmas políticos. México: Instituto de Investigaciones Jurídica, UNAM.

Chamorro, M. (2014). Desarrollo y crisis alimentaria: el caso de la seguridad alimentaria en Colombia. Revista CES Derech, 5(1), 57-65.

Cherni, J. (2001). La globalización de la insalubridad y la contaminación del aire urbano. EURE, XXVII (81), s.p.

Colombano, S. (2018). New Assumptions to guide SETI research. NASA . Recuperado de https://ntrs.nasa.gov/archive/nasa/casi.ntrs.nasa.gov/20180001925.pdf.

Costeau, J.-Y. (2014). Anexo 2: A bill of rights forfuture generations. Recuperado de https://archivos.juridicas.unam.mx/www/bjv/libros/8/3635/12.pdf.

Dávalos, P. (2010). Pueblos indígenas, estado y democracia. Buenos Aires: CLACSO. Ferrer, L. E Ferrer, J. (2008). El problema de la fundamentación filosófica de los derechos de las generacines futuras. Anuario Mexicano de Derecho Internacional, VIII, 487-507. 
Figueroa, R. (2007). Concepto de persona, titularidad del derecho a la vida y aborto. Revista de Derecho Valdivia, XX(2), 95-130.

Fortunat-Stagl, J. (2015). De cómo el hombre llegó a ser persona: Los orígenes de un concepto jurídico-filosófico. Revista de Derecho Valparaiso, XLV, 373-401.

Foucault, M. (2001). Defender la Sociedad. Buenos Aires: Fondo de Cultura Económica. Recuperado de http://www.uv.mx/tipmal/files/2016/10/MFOUCAULT-DEFENDER-LA-SOCIEDAD.pdf.

Frandsen, G. (2013). El hombre y el resto de los animales. Tinkuy, (20), 56-78.

Gudynas, E. (2010). La senda biocéntrica, valores intrrínsecos, derechos de la naturaleza y justicia ambiental. Tábúla Rasa, (13), 45-71.

Gudynas, E. (2011). Desarrollo, derechos de la naturaleza y buen vivir después de Montecristi. En G. Weber (Ed.), Debates sobre cooperación y modelos de desarrollo. Perspectivas desde la sociedad civil en el Ecuador (pp. 83-102). Quito: Centro de Investigaciones CIUDAD y Observatorio de la Cooperación al desarrollo.

Gudynas, E. E Acosta, A. (2011). La renovación de la crítica al desarrollo y el buen vivir como alternativa. Utopía y Praxis Latinoamericana, 16(53), 71-83.

Haber, A. (2011). Nometodología Payanesa: Notas de metodología indisciplinada. revista Chilena de Antropología, (23), XX-XX. Doi:10.5354/07191472.2011.15564

Hardy, T. (2001). IA: Inteligencia Artificial. Polis, Revista de la Universidad Bolivariana, $1(2)$, s.p.

Jongerden, J. E Ruivenkamp, G. (2010). Soberanía Alimentaria y el Principio campesino. Universitas, Revista de Ciencias Sociales y Humanas, (12), 31-45.

Kelsen, H. (2009). Teoría Pura del Derecho. Buenos Aires: Eudeba. Recuperado de http://cvperu.typepad.com/files/libro-teoria-pura-del-derecho-hans-kelsen.pdf Lalander, R. (2015). Entre el ecocentrismo y el pragmatismo ambiental Consideraciones inductivas sobre desarrollo, extractivismo y los derechos de la naturaleza en Bolivia y Ecuador. Revista Chilena de Derecho y Ciencia Política, 6 (1), 109-152.

López, A. (2014). Generaciones Futuras y Personalidad Jurídica. Dikaion, 23(2), 251-275.

Luján, M. (2018). Bots: La inteligencia artificial que ya nos toca. Recuperado de https://startpoint.cise.es/bots-la-inteligencia-artificial-que-ya-nos-toca/. Obtenido de https://startpoint.cise.es.

Mamián, D. (1992). El pensamiento andino. "Por la senda de Juan Chiles". Mopa Mopa, (8) 25-41. 
Mamián, D. (2000). Rastros y rostros de un camino por andar. Mopa Mopa, (14), 75-88.

Mamián, D. (2010). Urcunina: desiciones pollíticas y derechos culturales. Mopa Mopa, (20), 26-44.

Mamián, D. (2015). Mocondino en su historia. La abolición de su resguardo. Tendencias, XVI(2), 36-56.

Marín, M. (2010). La sociedad civil global en la gobernanza ambiental del sector agua en el mundo. Oasis, (15), 1-21.

Massini, C. (2017). Sobre dignidad humana y derecho. La noción de dignidad de la persona y su relevancia constitutiva en el derecho. Prudentia Iuris, (83), 49-72.

Mayorga, F. (2012). La propiedad territorial indígena en la provincia de Bogotá 18311857. Bogotá: Ediciones Academia Colombiana de Jurisprudencia.

Mayorga, F. (2013). Norma general, norma especial: el Código Civil de 1887 y la Ley 89 de 1890, un caso de regulación protectora de la minorías durante la Regeneración. Revista Mexicana de Historia del Derecho, XXVII, 159-182.

Mayorga, F. (2015). Datos para la historia de la propiedad territorial indígena en el suroccidente colombiano. Bogotá: Inédito.Trabajo encargado por el INCODER.

Meadows D., Randers J., Behrens II W, E Meadows L. (1972). The limits of the Growth. Washington: A Potomac Associates Book. Recuperado de http:// www.donellameadows.org/wp-content/userfiles/Limits-to-Growth-digitalscan-version.pdf.

Molina, J. (2014). Derechos de la naturaleza. Bogotá: Universidad Externado de Colombia.

Morris, M., Rodríguez, C., Orduz, N., E Buriticá, P. (2009). La Consulta Previa a pueblos indígenas: los estándares internacionales. Bogotá: Ediciones Uniandes.

Munévar, C. (2016). Los sujetos de las futuras generaciones: ¿quienes son los titulares de derechos. Opción, 32(79), 184-196.

Naciones Unidas. (1948). La Declaración Universal de Derechos Humanos. Recuperado de http://www.un.org: http://www.un.org/es/universal-declarationhuman-rights/

Navarro, O. (2013). Representación social del medio ambiente y de la contaminación del aire: efecto de imbricación de dos objetos. CES Psicología, 6(1), 104-121.

Organización de las Naciones Unidas. (1972). Declaración de Estocolmo sobre el medio ambiente humano Recuperado de http://www.ordenjuridico.gob.mx/ TratInt/Derechos\%20Humanos/INST\%2005.pdf 
Paredes, H. (2014). Derechos de la naturaleza en el ordenamiento constitucional vigente (trabajo de grado). Universidad Central del Ecuador, Quito, Ecuador. Perugache, J. (2014). La disolución de los resguardos quillasingas del Valle de Atriz del sur occidente colombiano 1940-1950. Procesos Históricos, (26), 140-157. Perugache, J. (2015). Voltear la Tierra para despertar la vida (tesis de maestría). Universidad Nacional de Colombia, Bogotá, Colombia.

Prieto, J. (2013). Derechos de la naturaleza. Fundamentos, contenido y exigibilidad constitucional. Quito: Corte Constitucional del Ecuador, Centro de estudios y difusión del derecho constitucional.

Ramírez, A. (2007). La etno-Constitución de 1991: criterios para determinar derechos comunitarios étnicos indígenas. Revista Estudios Socio-Jurídicos, 9(1), 130-156.

Red Nacional de Acueductos Comunitarios de Colombia. (2017). Iniciativa Legislativa para el fortalecimiento y defensa de los acueductos comunitarios. Colombia. Recuperado de https://drive.google.com/file/d/OB_VJhYycDFatSnUyc3NwTWRUVTQ/view.

Regan, T. (1999). Poniendo a las personas en su lugar. Teorema, XVIII(3), 17-37. Recuperado de https://dialnet.unirioja.es/descarga/articulo/4254786.pdf.

Regan, T. (2018). Ética medioambiental y Derechos animales. Recuperado de http://tomregan.free.fr/Tom-Regan-Derechos-Animales-y-etica-medioambiental.pdf.

Restrepo, E. (2013). Etnización de la negridad: la invención de las 'comunidades negras' como grupo étnico en Colombia. Popayán: Editorial Universidad del Cauca.

Reyes, M. E Moliner, M. (2009). Cuaderno IV: La Persona Jurídica. Madrid: Dikynson S. L.

Rodríguez, G. (2008). Animales, ¿En peligro de extinción o en peligro de que los extingamos? Ius et Praxis, 14(1), 301-315.

Rodríguez, J. (2001 ). Introducción a la prospectiva: metodologías, fases y explotación de resultados. Economía Industrial, 342, 13-20. Recuperado de https:// www.mincotur.gob.es/Publicaciones/Publicacionesperiodicas/EconomiaIndustrial/RevistaEconomiaIndustrial/342/1JesusRodriguez.pdf

Rueda, C. (2005). El reconocimiento de la jurisdicción especial indígena dentro del sistemajudicial nacional en Colombia. El debate de la coordinación. Estudios Sociojurídicos, 7, 339-374.

Sabato, E. (1951). Hombres y Engranajes. Recuperado de http://biblio3.url.edu. gt/Libros/2012/LYM/homb_engSaba.pdf.

Sabato, E. (2000). La Resistencia. Buenos Aires: Grupo Planeta. Recuperado de http://biblio3.url.edu.gt/Libros/sabato/resistencia.pdf. 
Sarango, L. (2016). El estado plurinacional y la sociedad intercultural: Una visión desde el Ecuador. Revista Direito e Práxis, 7(13), 636-658.

Simón, F. (2013). Derechos de la naturaleza: ¿innovación trascendental, retórica jurídica o proyecto político? Iuris Dictio, (15), 9-38.

Singer, P. (2003). Liberación Animal. The New York Review of Books $n^{\circ} 8 \mathrm{del} \mathrm{Vol-}$ umen $L$, s.p.

Solé, J. (2009). Física especulativa (o imaginària). Escola Catalana, 43(456), 13-15.

Stone, C. (1972). Should Trees Have Standing? Southern California Law Review, (45), 450-501.

Stone, C. (2010). Should the trees have standing? New York: Oxford University Press Inc.

Subcomandante Marcos. (25 de 12 de 1995). Palabra EZLN. Recuperado de http://palabra.ezln.org.mx/comunicados/1995/1995_12_25.htm

Vasco, L. (2007). Así es mi método de etnografía. Tabula Rasa Revista de Humanidade, (6), 19-52.

Vasco, L. G. (2010). Recoger los conceptos en la vida: una metodología de investigación solidaria. Recuperado de http://luguiva.net

Vasco, L. G. (2016). Desechar los conceptos en la vida. Recuperado de http://www. luguiva.net/admin/pdfs/DESECHAR\%20LOS\%20CONCEPTOS\%20 EN\%20LA\%20VIDA.pdf

Velasco, Á. (2012). Cómo llegar al presente: recuperación de la memoria para las luchas de hoy. Mopa Mopa, (21), 145-155.

Villalba, J. (2016). Problemas bioéticos emergentes de la inteligencia artificial. Diversitas: Perspectivas en Psicología, 12(1), 137-147.

\section{Jurisprudencia}

Corte suprema de Justicia. Sentencia STC-4360 (Amazonía).

Corte Constitucional. Sentencia C-133, C-133.

Corte Constitucional de Colombia. Jurisprudencia Constitucional, T-001.

Corte Constitucional de Colombia. Sentencia T. 622 (Río Atrato).

Corte Constitucional de Colombia. Sentencia T-455 (Control de Tutela).

Corte Constitucional de Colombia. Sentencia T-823 (Control de tutela). 